\title{
A STUDY ON DIFFERENT APPROACHES OF SIX-SIGMA AND KNOWLEDGE MANAGEMENT INTEGRATED MODELS TO IDENTIFY THE LEVERAGING EFFECTS
}

\author{
LAL MOHAN BARAL \\ Department of Engineering and Management, Faculty of Engineering, "Lucian Blaga" University of Sibiu, \\ Sibiu, Romania. \\ $\&$ \\ Department of Textile Engineering, Faculty of Engineering, Ahsanullah University of Science and Technology, \\ Dhaka, Bangladesh, baraltex@aust.edu, Ialmohan_baral@yahoo.com \\ CLAUDIU VASILE KIFOR \\ Department of Engineering and Management, Faculty of Engineering, "Lucian Blaga" University of Sibiu, \\ Sibiu, Romania, claudiu.kifor@ulbsibiu.ro
}

\begin{abstract}
The purpose of this paper is to review the different models which integrate Six Sigma and Knowledge Management (KM) approaches and also to identify the advantages and disadvantages of those models. Based on literature, the available Six Sigma and KM models have been reviewed. All the models have been critically analysed according to their structure and end users and finally the advantages and disadvantages are enlisted. The Overview expressed that more or less every model has been proposed aiming to the specific endues and each model has both strength and weakness for application to all sectors. In this article, the advantages and disadvantages of existing Six Sigma-KM models have been identified. This study may offer some guidance to find new directions to eliminate the week points of those models by introducing new ideas and methodologies.
\end{abstract}

Keywords: Knowledge management, Six Sigma, integrated model, leveraging effects.

\section{Introduction}

Knowledge management has an important role in Six Sigma and process improvement. The concept of tacit knowledge, or the knowledge that "is located in individual people's heads" (Mercer, 1995) includes the things people know about a process and do, but are generally not written down. Explicit knowledge, which is documented, also exists in the process through procedures and reports. A key role of the leaders in Six Sigma, the Master Black Belt and Black Belt, is "facilitating the sharing of knowledge" (George, 2002), both tacit and explicit. Knowledge might be transferred, shared, or reused, through the use of methods such as mentoring, communities of practice, or experts. That process improvement knowledge should be gained from production procedure and the process being improved (Stevens, 2006). Six Sigma deployment needs access to critically important knowledge to be successful, yet this knowledge is often lost or inaccessible. A review of the literature identified how knowledge can be shared and transferred (George, 2002) and that essential knowledge exists within processes (Davenport \& Prusak, 2000).

A key to Six Sigma is the ability of project leaders to understand or to gain knowledge of the people and processes, in order to improve the product quality (Stevens, 2006). Six Sigma is a "learning tool" (Pande et al., 2000). Experts knowledgeable in the tools and processes of Six Sigma seek people within the processes that may have knowledge and will assist for reducing variation. On the other hand, Knowledge management (KM) can impact organizations and organizational performance at several levels, such as; people, processes, products and the overall organizational performance (BecerraFernandez and Sabherwal, 2008). KM processes can impact organizations at these four levels in the two main ways. First, KM processes can help creating knowledge, which can contribute to improve the performance of the organizations along with above four dimensions. Second, it can directly cause improvements along with these four dimensions (Becerra-Fernandez and Sabherwal, 2010) 
The purpose of this study is to understand the interaction of knowledge management concepts and the Six Sigma deployment process. To achieve that goal, a number of models integrating Six Sigma and KM have been reviewed. All the existing models have been critically analysed according to their structure and end users in order to identify both strength and weakness of those approaches.

\section{Knowledge creation opportunities within Six Sigma}

Six Sigma is a process designed for changing other processes (Wu and Lin, 2009). One of its major purposes is to solve problems by designing new solutions to improve the manufacturing or production process. According to X.P. Tracy Zou and W.B. Lee (2010), the solutions or the improvement plans are the ultimate new knowledge that is generated from Six Sigma teams, during the application of DMAIC methodology.

The model used in Six Sigma deployments to execute project work is known as Define, Measure, Analyze, Improve and control, or DMAIC (George, 2002), depicted below (Figure 1).

Figure:1 The DMAIC methodology with gate review

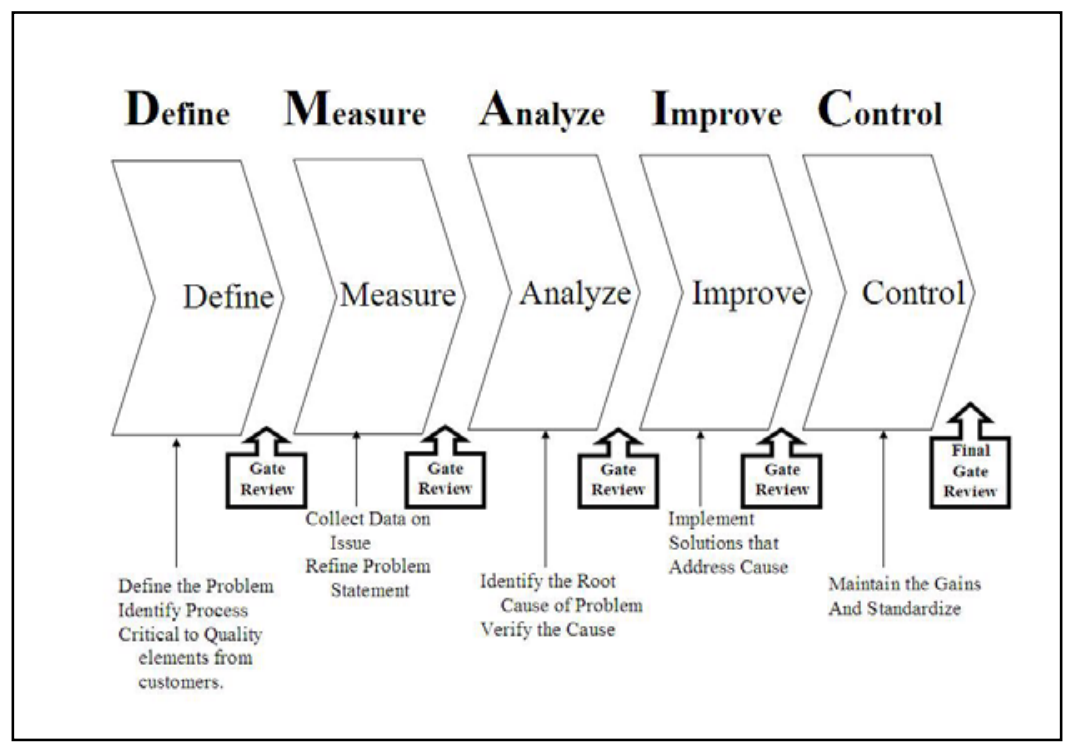

Source: (Stevens, D.E., 2006)

The figure identifies the types of activities that will be executed in each of the phases of this improvement process. DMAIC is grounded in the original TQM theory of Plan, Do, Check, and Act (PDCA) identified by Deming (1986) as the Shewhart cycle. Within the DMAIC model there are gates or tollgates (Figure: 1), which should be reviewed (George, 2002). The gates are reviewed at each phase of the project, where the "appropriate managers, master black belts, and champions have a chance to listen to the team present its work" and to "ask questions to ensure the team is staying focused"(George, 2002). Important guidance is provided to the team and "sources of information"(George, 2002) are provided those working on the project by executive management. Management also makes decisions at each of these gates on whether projects should continue. This is another critical stage where knowledge is exchanged within the Six Sigma deployment and an opportunity to evaluate the effect of knowledge management on a Six Sigma deployment.

Chuni Wu and Chinho Lin (2009) also identified the knowledge creation opportunities and types of knowledge created, in a Six Sigma project. They mentioned that there are two basic environments (such as internal and external) within Six Sigma project implementation where knowledge can be created. Six opportunities have been identified within the critical factors involved for a successful Six Sigma project lying on those two environments.

\section{Different approaches related to Six Sigma and KM integration} described.

In this section, a number of initiatives regarding the integration of KM with Six- Sigma will be 
Raytheon Six Sigma model is an integrated model in between Six Sigma and KM concepts. In 1988, Daniel Burnham moved from Allied Signal to become the new CEO of Raytheon, and started there, this new concept by reconstructing the traditional Six Sigma methodology. Raytheon Six Sigma differs from the typical Six Sigma initiatives in several ways. A new methodology is adopted in Raytheon Six Sigma with Six Step process model (such as Visualize, Commit, Prioritize, Characterize, Improve and Achieve) instead of conventional DMAIC (Define, Measure, Analyse, Improve and Control) methodology. This model also integrated a knowledge management strategy, which was leveraged into the knowledge management philosophy. As a new invention "Achieve, celebrate and share knowledge" step has been added with traditional DMAIC process (Sally Lanyon, 2003). Raytheon introduced a four step process containing Create, Capture, Share and Reuse for integrating KM with their Six Sigma activities.

Dr. Ricky Yeung (2004), founder president of Six Sigma Society of Hong Kong has proposed an integrated Six Sigma and KM model, called integrated knowledge representation (IKR) model. According to this model, each content can be represented within 5W1H framework (originated in "The role of the 5W's, Shuman, E.L., 1903) in respect of the domains of interest. He has also developed a conceptual framework for Knowledge repository system, which is managed by an IT platform called Total Enterprise Knowledge Integrated Platform (TEKIP). Share- Learn- Trust- Communicate as KM cycle are also integrated with in this platform. TEKIP platform focuses on knowledge evolution process, knowledge gathering, knowledge organization and storage, knowledge learning, knowledge nomination, and discussion. It also provides various tools (grouped in different workbenches) to achieve the above objectives.

A Process-based Knowledge Creation and Opportunities model has been proposed by Chuni Wu and Chinho Lin (2009) in order to explore the knowledge creation opportunities and types of knowledge created, in a Six Sigma project. This model integrates the critical factors involved for a successful Six Sigma project. They tried to list the types of knowledge according to Nonaka et al.'s (2000) theory of knowledge creation in that the interactive spiral process of SECI ba modes (Socialization, Externalization, Combination and Internalization), which would connect and convert tacit and explicit knowledge. They have also proposed an implementation process for a Six Sigma knowledge creation system.

Herbert Nold III (2011) proposed a model by merging Nonaka's SECI knowledge creation cycle with six-sigma SIPOC processes to increase the speed and effectiveness of management decision-making, work groups, project teams, and any other value adding activity. The basis of the process is the SECI cycle (socialization, externalization, combination, and internalization) to describe the cyclical process of converting tacit knowledge to explicit knowledge and back again to tacit knowledge in the form of new knowledge that adds to the body of organizational knowledge. Completing a SECI, cycle adds to the organizational body of knowledge thereby enhancing the organization's capability to act (Sabherwal \& Becarra-Fernandez, 2003).

The above model is proposed based on the Argyris and Schon's (1978) double loop learning, whereby individuals learn by examining and challenging fundamental assumptions and principles. Double loop learning contrasts with single loop learning whereby individuals limit cognitive efforts to simple problem solving and error correction (Jashapara, 2003).Overlaying interlocking SECI knowledge creation cycles over each step of the SIPOC process creates a visual representation of a problem solving or decision-making process whereby all actors are engaged in continuous tacit to explicit knowledge conversion and regeneration, challenging fundamental assumptions at each stage of the process.

X.P. Tracy Zou and W.B. Lee (2010) have conducted a study in order to identify the cultural influence on knowledge flow within Six Sigma teams. For this study, they have considered Chinese manufacturing plant and Chinese workers, whom are favouring a holistic approach rather than an analytical approach that are closely related to the western culture. They have considered four factors such as i) the type of the knowledge, ii) the source of knowledge, iii) the recipient of knowledge and iv) the context of knowledge (cultural influence) for their study which are closely associated with knowledge flows (Qing, 2008). Finally they have proposed a framework of Knowledge flow for Six Sigma teams, which integrates Technical knowledge, Practical Knowledge, Critical Knowledge and Voice of the Customers.

Robert E. Paladino and Kenna B. Newman (2004) have introduced a model which integrates Balanced Scorecard, Six Sigma effort inspired by Motorola and KM efforts across the company, when they were working in Crown Castle International USA. The basic aim of the above model is, if the balanced Scorecard dashboard contains red or underperforming results, then a business owner may start a remedial Six Sigma project. If the Scorecard dashboard is green, then GP team may capture a best practice or gem 
for reuse in the KM system. They also applied the above methodology on a "Job Close" project operated by Crown Castle International. Applying the Six Sigma methodology resulted in a powerful quick win which has since been converted into a Best Practice reflected companywide in the knowledge management system. Crown Castle International received the BSC Collaborative Hall of Fame award and was recognized as a best practice by APQC for the above initiatives.

Identification of Advantages and Disadvantages of existing models.

According to the above critical analysis, possible advantages and disadvantages have been listed in the table below:

Table: 1- Advantages and Disadvantages of existing models

\begin{tabular}{|c|c|c|c|}
\hline $\begin{array}{l}\text { Srl. } \\
\text { No. }\end{array}$ & $\begin{array}{l}\text { Name of the } \\
\text { Approaches/M } \\
\text { odels }\end{array}$ & Advantages & Disadvantages \\
\hline 01 & $\begin{array}{l}\text { Raytheon SS } \\
\text { and KM } \\
\text { integrated } \\
\text { model }\end{array}$ & $\begin{array}{l}\text {-This approach added value for the } \\
\text { customer } \\
\text {-Tools used for improving processes } \\
\text { through value oriented knowledge based } \\
\text { decisions } \\
\text { - A new culture geared towards } \\
\text { maximizing customer value, minimizing } \\
\text { bureaucracy and maximizing the } \\
\text { potentiality of every employee. }\end{array}$ & $\begin{array}{l}\text {-It is a modified model and } \\
\text { different from the typical Six } \\
\text { Sigma, which includes some } \\
\text { other extra steps. } \\
\text { - Raytheon SS has integrated } \\
\text { only four steps of KM cycle } \\
\text { such as: create, capture, } \\
\text { share and reuse. }\end{array}$ \\
\hline 02 & TEKIP model & $\begin{array}{l}\text { - The every content is representing in } \\
5 \mathrm{~W} 1 \mathrm{H} \text { framework according to the domain } \\
\text { of interest. } \\
\text { - A conceptual framework has been } \\
\text { presented for Knowledge repository } \\
\text { - Knowledge has been managed by an IT } \\
\text { platform (TEKIP) which includes } \\
\text { knowledge learning centre, knowledge } \\
\text { incubation centre, knowledge nomination } \\
\text { centre and knowledge audit centre. }\end{array}$ & $\begin{array}{l}\text {-This system has very little } \\
\text { interaction with basic six } \\
\text { sigma steps. Only some } \\
\text { documents related to the } \\
\text { tools and activities can be } \\
\text { stored. } \\
\text { - Only four steps of KM } \\
\text { cycle (Share-Learn-Trust- } \\
\text { Communicate) has been } \\
\text { introduced. }\end{array}$ \\
\hline 03 & $\begin{array}{l}\text { Process-based } \\
\text { Knowledge } \\
\text { Creation and } \\
\text { opportunities } \\
\text { model }\end{array}$ & $\begin{array}{l}\text { - In this model, knowledge creation } \\
\text { opportunities have been identified within } \\
\text { Six Sigma project. } \\
\text { - The SECI ba modes have been used to } \\
\text { convert the identified knowledge. }\end{array}$ & $\begin{array}{l}\text {-Only SS critical success } \\
\text { factors are considered rather } \\
\text { than DMAIC process for } \\
\text { identifying the opportunities. } \\
\text { - KM procedure is not clearly } \\
\text { explained. }\end{array}$ \\
\hline
\end{tabular}




\begin{tabular}{|c|c|c|c|}
\hline 04 & $\begin{array}{l}\text { Knowledge } \\
\text { flow in Chinese } \\
\text { SS teams } \\
\text { model }\end{array}$ & $\begin{array}{l}\text {-In this model, knowledge creation } \\
\text { opportunities within SS team activities } \\
\text { have been identified. } \\
\text {-Technical knowledge, practical } \\
\text { knowledge and critical knowledge are } \\
\text { integrated with Voice of Customer }\end{array}$ & $\begin{array}{l}\text {-Only Chinese cultural } \\
\text { environment is considered. } \\
\text { - KM procedure is not clearly } \\
\text { explained. } \\
\text { - Tacit and Explicit } \\
\text { knowledge are not clearly } \\
\text { defined. }\end{array}$ \\
\hline 05 & $\begin{array}{l}\text { SECI/SIPOC } \\
\text { continuous } \\
\text { loop model }\end{array}$ & $\begin{array}{l}\text {-Knowledge creation within SIPOC } \\
\text { process has been explained. } \\
\text {-Tacit and Explicit knowledge has been } \\
\text { separated and maybe applied to any } \\
\text { organizational activities. }\end{array}$ & $\begin{array}{l}\text {-Only Knowledge converting } \\
\text { process has been explained } \\
\text { through SECI modes but KM } \\
\text { process has not been clearly } \\
\text { explained. }\end{array}$ \\
\hline 06 & $\begin{array}{l}\text { SS, KM and } \\
\text { Balanced } \\
\text { Scorecard } \\
\text { integrated } \\
\text { model }\end{array}$ & $\begin{array}{l}\text {-This model integrates business Strategy, } \\
\text { business process, customer surveys, } \\
\text { Balance Scorecard and KM }\end{array}$ & $\begin{array}{l}\text {-Knowledge identification is } \\
\text { not clearly explained } \\
\text { - KM has performed through } \\
\text { social media and } \\
\text { communities of practice only }\end{array}$ \\
\hline
\end{tabular}

\section{Conclusion}

The academic contribution of this research includes a wide range of literature reviews related to integration of Six Sigma and KM concepts. The available literature focused that the existing SS and KM integrated models/approaches have been proposed considering the related application area of the developer. All models/ approaches showed both advantages and disadvantages (table:1), which are the barrier to generalize the use of those models to all sectors. This study may offer some guidance to find new directions to eliminate the weak points of those models by introducing new ideas and methodologies.

\section{Acknowledgements}

This research has been done within Doctoral studies under the financial support of Erasmus Mundus Mobility with Asia (EMMA). Authors are very much thankful to the EMMA management team for their support.

\section{References}

- Argyris, C.; Schon, D. (1978) Organizational Learning: A Theory of Action Perspective, Reading, MA: Addison Wesley.

- Becerra-Fernandez, I.; Sabherwal, R. (2008) Individual, group, and organizational learning. in Knowledge management: An evolutionary view, ed. I. Becerra-Fernandez and D. Leidner, 13-39. Armonk, NY: M.E. Sharpe Publication.

- Becerra-Fernandez, I.; Sabherwal, R. (2010) Knowledge Management Systems and Processes M.E. Sharpe Publication, Armonk, New York.

- Davenport, T.; Prusak, L. (2000) Working Knowledge, Boston: Harvard Business School Press.

- Deming, W. (1986) Out of the Crisis, Cambridge, MA: Massachusetts Institute of Technology.

- George, M. (2002) Lean Six Sigma. New York: McGraw-Hill.

- Herbert, N.(2011) Merging Knowledge Creation Theory with the Six-Sigma Model for Improving Organizations: The Continuous Loop Model, International Journal of Management, Vol. 28, No. 2.

- Jashapara, A. (2003) Cognition, culture, and competition: An empirical test of the learning organization, The Learning Organization, Vol. 10(1), pp. 31-50. 
- Lanyon, S. (2003) “At Raytheon Six Sigma Works, Too, To Improve HR Management Process”, The Journal of Organizational Excellence; Autumn; Vol. 22(4).

- Mercer, N. (1995), The Guided Construction of Knowledge. Philadelphia: Multilingual Matters LTD.

- Nonaka, I.; Toyama, R.; Konno N.(2000) SECI, Ba and leadership: a unified model of dynamic knowledge creation, Long Range Planning, Vol. 33, No. 1, pp. 5-34.

- Paladino, R. E.; Newman K.B.(2004) Integrating Balanced Scorecard, Six Sigma and Knowledge Management to Drive Value at Crown Castle, APQC. Available at: www.apqc.org, Accessed (date: 2012/09/12)

- Pande, P.; Neuman, R.; Cavanagh, R. (2000) The six sigma way team field book. New York: McGraw-Hill.

- Qing, X. (2008), The culture relativity in the knowledge flow: an integrative framework in the Chinese context, Chinese Management Studies, Vol. 2, No. 2, pp. 109-121.

- Sabherwal, R.; Becarra-Fernandez, I.(2003) An empirical study of the effect of knowledge management processes at individual, group and organizational levels. International Journal of Decision Science, Vol. 34 No. 2, pp. 225-261.

- Stevens, D. E.(2006) The Leveraging Effects of Knowledge Management Concepts In the Deployment of Six Sigma in a Health Care Company, Ph.D. Thesis, Walden University , USA.

- $\quad$ Tracy Zou, X. P.; Lee, W.B.(2010) A study of knowledge flow in Six Sigma teams in a Chinese manufacturing enterprise, The Journal of information and knowledge management systems, Vol. 40 no. 3/4 , pp.390-403.

- Wu, C.; Lin, C.(2009) Case study of knowledge creation facilitated by Six Sigma, International Journal of Quality \& Reliability Management, Vol. 26, No. 9, pp. 911-932

- Yeung, R.(2004) Integrating Six Sigma with Knowledge Management, Lecture slides in City University Hong Kong .Available at: www. six sigma.org.hk, Accessed (date: 2012/10/12). 